\title{
"GESTÃO DE ILEGALISMOS E O TEATRO DA DISCIPLINA: os casos de falta grave por posse, utilização ou fornecimento de celular em uma unidade prisional de Curitiba/PR no ano de 2017"
}

\section{André Ribeiro Giamberardino?}

\section{Palavras-Chave}

execução penal/ falta grave/ celulares/ ilegalismo/ sociologia da prisão

\section{SUMÁRIO}

1. Introdução. 2. Notas metodológicas preliminares. 3. Base teórica: o sistema disciplinar na crítica sociológica e jurídica. 3.1 Ilegalismos e a construção da ordem interna nas prisões; 3.2 Do sistema disciplinar e a discricionariedade administrativa da autoridade penitenciária. 4. As faltas graves referentes a posse ou uso de telefone celular (ou componente acessório) no ano de 2017 na Casa de Custódia de Curitiba (CCC). 5. Considerações finais. Referências.

1 Professor Permanente do Programa de Pós-graduação em Direito da UFPR e Colaborador do Programa de Pós-graduação em Sociologia da UFPR.

\section{Resumo}

A Lei 11.466/2007 inseriu a posse, utilização ou fornecimento de celular, rádio ou similar como hipótese de falta grave, conforme o art. 50, VII, da Lei de Execução Penal. Hoje, o que se vê é a absorção da proibição dos celulares pelas práticas de gestão e construção da ordem interna, aqui tomadas a partir do conceito foucaultiano de ilegalismo e de algumas hipóteses fundantes da sociologia das prisões. A pesquisa traz recorte empírico com todos os casos de falta grave em uma unidade de Curitiba/PR em 2017, totalizando 16 (dezesseis), colocando a questão de quais seriam os parâmetros determinantes para imputação de responsabilidade disciplinar por telefones celulares ou similares apreendidos a este ou àquele preso. A partir da análise dos processos e observação participante, evidencia-se como na grande maioria dos casos os presos que assumem a responsabilidade pelos itens apreendidos o fazem por não terem família na região ou por terem uma pena remanescente alta, tendo por objetivo a contraprestação pecuniária ou outros favores, não sendo os verdadeiros donos dos aparelhos. A aplicação da sanção disciplinar, com conhecimento da falsidade da confissão, indica que o Estado opera como gestor de ilegalismos e não a partir do binômio lícito/ilícito oriundo da norma jurídica. 


\title{
"ILLEGALISMS AND THE THEATER OF DISCIPLINE: the 2017' cases of unlawful possession, use and provision of mobile phones in a prison unit in Curitiba/PR"
}

\author{
André Ribeiro Giamberardino
}

Key words

penitentiary law/ mobile phones/ illegalisms/ sociology of prison

\begin{abstract}
In2007, the law11.466inserted the possession, use and provision of mobile phones, radio or similar in prison as hypothesis of serious misconduct. Today, what is seen is the absorption of the prohibition by the practices of management and construction of the internal order, taken here from the Foucaultian concept of illegalism and some hypotheses found in the sociology of prisons. The research brings an empirical sample with all the cases of serious misconduct by this reason in a prison of Curitiba in 2017, totaling 16 (sixteen), being asked the question of which would be the determining parameters for imputation of disciplinary responsibility by cellular phones seized to this or that prisoner. From the analysis of the processes and participant observation, it is evident how, in the great majority of cases, the prisoners who take responsibility for the seized items do so because they do not have family in the region, because they have a high remnant penalty or to get some form of payment, not being the real owners of the devices. The application of the disciplinary sanction, with knowledge of the falsity of the confession, indicates that the State operates as manager of illegalisms and not from the legal/illegal binomial.
\end{abstract}




\section{Introdução}

Publicada em 28 de março de 2007, a Lei 11.466 (2007) inseriu a posse, utilização ou fornecimento de "aparelho telefônico, de rádio ou similar, que permita a comunicação com outros presos ou com o ambiente externo", como hipótese de falta disciplinar de natureza grave, conforme tipificação constante do art. 50, VII, da Lei de Execuções Penais, doravante LEP (Lei 7.210/84): "Art. 50. Comete falta grave o condenado à pena privativa de liberdade que: (...) VII - tiver em sua posse, utilizar ou fornecer aparelho telefônico, de rádio ou similar, que permita a comunicação com outros presos ou com o ambiente externo".

Originado do PL 136/2006 do Senado Federal, a justificativa do projeto de lei se baseou na demanda por controle da articulação de "ações criminosas a partir dos estabelecimentos penais", com menção expressa à "onda de violência no Estado de São Paulo, em que o PCC alvejou várias instituições públicas e privadas da capital"2, fato datado de 2006 e que motivou a tramitação do projeto.

Pouco mais de dez anos depois, porém, o que se vê é a absorção e cooptação da proibição abstrata dos celulares pelas práticas concretas de gestão, aqui tomadas a partir do conceito foucaultiano de ilegalismo e de algumas hipóteses fundantes da sociologia das prisões na temática da construção da ordem interna.

Importante ter em conta, desde logo, que o reconhecimento de que o preso praticou a referida falta grave o sujeita a sanções administrativas previstas em lei (art. 53, LEP), como o isolamento e a suspensão ou restrição de direitos. Por decisão do diretor da unidade, o preso pode ficar por até 30 (trinta) dias sem a visita do cônjuge, companheira, filhos, parentes e amigos, bem como sem acesso ao pátio de sol e outras atividades. Posteriormente, caso a falta grave seja confirmada pelo juízo, outras consequências podem impactar em sua pena, como o reinício da contagem do tempo para progressão de regime e a perda de parte dos dias remidos por trabalho ou estudo.

Durante o ano de 2017, atuei como defensor público nos processos administrativos disciplinares em unidade prisional situada na região metropolitana de Curitiba/Paraná - a Casa de Custódia de Curitiba, doravante "CCC". Agregada à experiência profissional, parcial por definição, foi colocada a questão de pesquisa sobre quais seriam os parâmetros determinantes para imputação de responsabilidade disciplinar por telefones celulares ou similares apreendidos a este ou àquele preso. E o que fica claro é que, na imensa maioria dos casos, os presos que se apresentam como donos ou responsáveis pelos itens proibidos apreendidos não o são, de fato. Mesmo assim, as "confissões" são aceitas pelo Estado no âmbito do processo administrativo disciplinar (PAD), sendo muitas vezes, como se indica a seguir, afastadas em Juízo. Os dados apresentados dizem respeito à integralidade das faltas graves correspondentes à apreensão de celular ou acessório durante o ano de 2017, na citada unidade prisional.

\section{Notas metodológicas preliminares}

Parece importante e pertinente apresentar brevemente algumas cautelas metodológicas, tratando-se a presente pesquisa, em parte, de uma observação incognito no ambiente prisional. São as questões de pesquisa que devem levar à decisão pelos instru- 
mentos metodológicos mais adequados, e não o contrário: no caso, por razões indicadas a seguir, optei pela análise documental de processos (públicos) agregada à observação participante como pesquisador, mas a partir de posição ocupada, no interior da unidade, como profissional do sistema de justiça. Importante registrar que se está a seguir a premissa pela qual toda pesquisa qualitativa não deve estabelecer um conceito bem definido no início e formular hipóteses a serem testadas, mas sim desenvolver e refinar conceitos e hipóteses no processo de pesquisa (Angrosino, 2009, p. 9), o qual ocupou efetivamente todo o ano de 2017.

Os resultados aqui apresentados indicam a prevalência de parâmetros extralegais na imputação de responsabilidade disciplinar a presos que, sabidamente, não eram os verdadeiros "culpados" pelos celulares ou itens associados, mas assumem tal condição diante do Estado em respeito a normas e dinâmicas criadas pela própria população carcerária ou que regulam as interações entre a população carcerária e o corpo de funcionários da unidade prisional.

Há várias formas para se proceder a uma pesquisa no cárcere, inclusive a partir da condição de profissional do sistema de justiça (Martin, 2000, p. 216), ainda que essa não seja a mais usual. A colheita de dados nessas circunstâncias impõe uma série de cautelas de ordem ética e precauções metodológicas que devem ser, desde logo, registradas.

A apresentação de si mesmo aos demais atores na condição de profissional, e não de pesquisador, contribui para facilitar alguns aspectos relacionados ao acesso a um campo tão fechado ${ }^{3}$, além de fazer com que se passe a ser parte do próprio objeto, sem qualquer pretensão de análise "neutra" e à distância. O desenvolvimento de uma relação cooperativa para com o respectivo departamento penitenciário, por exemplo, é apontado como etapa importante para a consecução dos objetivos de qualquer trabalho nesse âmbito (Martin, 2000, p. 218-219; Apa et al, 2012, p. 468-469), até porque a autorização é ato imprescindível para possibilitar o acesso. No caso, tal autorização não se fez necessária porque a observação se deu na condição de profissional do sistema de justiça, cuja presença é funcional e necessária nos depoimentos e reuniões para julgamento das infrações disciplinares, sob pena de nulidade, nos termos da Súmula n. 533, do Superior Tribunal de Justiça:

Para o reconhecimento da prática de
falta disciplinar no âmbito da execução
penal, é imprescindível a instauração de
procedimento administrativo pelo dire-
tor do estabelecimento prisional, assegu-
rado o direito de defesa, a ser realizado
por advogado constituído ou defensor
público nomeado (DJe 15/06/2015).

A presença relativamente frequente contribui na redução das alterações de rotina que são reações defensivas diante de qualquer membro externo ao campo. Nesse sentido a reflexão de Cicourel:

A participação mais intensa tem a vantagem de expor mais o observador tanto

3 Sobre os vários dilemas presentes em pesquisas em prisões, a partir de experiência de programa de investigação sobre a reincidência criminal e violência nas prisões de São Paulo, v. Adorno, S. (1991). "A prisão sob a ótica de seus protagonistas: itinerário de uma pesquisa". Revista Tempo Social, 3(1-2), 7-40; Bodê de Moraes, P. (2013). "A identidade e o papel de agentes penitenciários". Revista Tempo Social, 25(1), 131-147. 
à rotina quanto às atividades incomuns do grupo estudado. Supõe-se que quanto mais intensa for a participação, por um lado mais ricos serão os dados, e por outro lado maior será o perigo de "virar nativo" além de, como consequência de se adotar a maneira de perceber e interpretar o ambiente que é própria do grupo, tornar-se cego para muitas questões importantes cientificamente (Cicourel, 1980, p. 93).

Porém, tal condição cria limites éticos à utilização de alguns instrumentos como, por exemplo, a entrevista. Fundamental esclarecer, desde logo, que os instrumentos metodológicos aqui utilizados foram prevalentemente a análise documental de processos de execução penal que são públicos, inclusive no que tange ao conteúdo dos depoimentos prestados pelas pessoas presas no âmbito dos respectivos processos administrativos disciplinares.

Em conjunto à análise documental de tais processos, não parece haver qualquer problema na sua compreensão a partir de elementos fornecidos por observação participante, sobretudo no que se refere a falas de pessoas presas e de servidores do estabelecimento penal que não são reduzidas a termo nos autos; muitas delas, inclusive, realizadas em um momento formal que é a sessão do Conselho Disciplinar da unidade para julgamento da falta grave mas que, por opção da autoridade administrativa e para fins de celeridade e agilidade, não são inseridas na ata da reunião, a qual segue um modelo padrão bastante sucinto.

Afinal, a observação participante pode ser vista mais como estratégia de coleta de dados que como método de pesquisa propriamente dito (Haguette 2000, p. 70), com bastante flexibilidade quanto ao papel do observador ser encoberto ou explícito:
A observação clandestina é também escolhida no caso de situações sociais complexas ou de meios quase inacessíveis sem essa dissimilação. Nesta circunstância, é uma lógica de acessibilidade que orienta a estratégia. (...). Este é o caso principalmente dos estudos sobre as instituições totais (o hospital psiquiátrico, a prisão, o exército), ou sobre grupos fechados, tais como as gangues ou as seitas. (Jaccoud e Mayer, 2008, p. 265)

Na mesma linha a ponderação de S. Chauvin:

\begin{abstract}
A observação incognito, além disso, coloca um problema deontológico, já que ela priva os atores de um consentimento informado de sua participação na pesquisa. As informações colhidas sobre eles são feitas à revelia. Esta recriminação clássica feita à observação dissimulada, não pode, no entanto, ser mantida senão radicalizando sua especificidade e exagerando o caráter informado do consentimento dos pesquisados em outros métodos. Na realidade, uma observação completamente às claras é praticamente impossível, salvo se o meio estudado for um recinto social com poucas pessoas e pouco transitado. (Chauvin, 2015, p. 129-130).
\end{abstract}

O que se destaca é um papel ativo do observador como modificador do contexto e ao mesmo tempo como receptáculo de influências do próprio contexto observado (Haguette, 2000, p. 73). Trata-se de coletar dados "através de sua participação na vida cotidiana do grupo ou organização que estuda" (Becker, 1999, p. 47), ao invés de se buscar demonstrar relações entre variáveis abstratamente definidas, buscando compreender as interações e o comportamento dos atores sociais diante de situações que fazem parte da rotina. Daí a relevância, segundo o autor, de se estabelecer interações diretas com os participantes no intuito de compreender e desvelar as interpretações que eles têm sobre os acontecimentos ob- 
servados e registrados como pertinentes à pesquisa.

Sobre a dificuldade própria desse tipo de pesquisa no direito, vale enfatizar a preocupação relevante em se "estabelecer a necessária distância para desnaturalizar e avaliar, com certa objetividade, os dados e as representações vivenciadas no campo" (Baptista, 2017, p. 95). Por objetividade e objetivação não se faz referência, evidentemente, a qualquer pretensão de neutralidade. Afinal, "não existe um argumento epistemológico absoluto que permita decidir observar às claras ou não: o importante é manter a perspectiva de uma postura reflexiva, atenta aos efeitos da escolha de método sobre a percepção do objeto" (Chauvin e Jounin, 2015, p. 128). Nesse sentido é que a atividade de pesquisa por vezes se confundiu ou sobrepôs à atividade de defensor público, por exemplo, quando as respostas - sempre orais - dos membros do Conselho Disciplinar às linhas de argumentação desenvolvidas pela defesa no sentido de insuficiência de provas de autoria, durante as sessões de julgamento, são trazidas como componentes pertinentes na interpretação dos dados obtidos dos processos elencados.

No caso concreto, a clareza das relações entre os depoimentos dos presos e suas "confissões impossíveis", de um lado, e a banalidade da aplicação da sanção disciplinar a "qualquer um deles", de outro, são elementos que se revelaram de forma muito explícita dentro do jogo do sistema disciplinar. Porém, se o acesso inicial ao campo fosse na forma de pesquisa acadêmica, haveria que se pedir autorização prévia à direção e haveria, certamente, uma resistência maior no registro e explicação de tais dinâmicas.
A entrevista é um dos instrumentos qualitativos mais interessantes e frequentemente utilizados em pesquisas no âmbito prisional, tanto com pessoas presas como com funcionários do sistema penitenciário (por exemplo, v. Bodê de Moraes, 2013; Dias, 2013; Braga, 2014; Sá e Simões e Bartolomeu, 2017; Angotti, 2017, p. 161-188). Todavia, diversamente da observação participante incognito, há problemas éticos em se "entrevistar alguém" sem que o entrevistado saiba de tal condição, além da evidente dificuldade em se colher informações sobre atos ilícitos, ainda que informada a condição de sigilo, diante de alguém identificado como profissional do sistema de justiça.

Por fim, busquei tabular os dados apresentados a partir dos processos de execução penal dos presos custodiados na referida unidade prisional, seguidos da articulação de hipóteses a partir do que eles indicam e de elementos relevantes observados na interação entre os atores que os produziram.

Não há e nem poderia haver pretensão de representatividade em relação ao que se poderia chamar "índice real" de telefones celulares ou similares que circulam entre as três galerias da Casa de Custódia de Curitiba. A atenção às datas das faltas registradas indica que foram relativamente poucas, se considerado o lapso temporal de um ano. É evidente que há uma enorme cifra oculta no âmbito do sistema disciplinar, o que é coerente com os estudos mais importantes sobre a construção da ordem interna nas prisões. De todo modo, os dados são suficientemente relevantes para contribuir na compreensão crítica das dinâmicas e interações que determinam a atividade de registro e formalização das condutas transgressivas por parte dos servidores do sistema penitenciário, construindo o que é, sem 
meias palavras, um verdadeiro teatro que traz à cena a falácia do sistema disciplinar em meio a tantas outras falácias características do discurso penitenciário, mas que em seu conjunto determinam uma bem-sucedida gestão diferenciada de ilegalismos.

\section{Base teórica: o sistema disciplinar na crítica sociológica e jurídica}

\subsection{Ilegalismos e a construção da ordem interna nas prisões}

O conceito de ilegalismo permite a superação da dicotomia legal/ilegal através da abordagem da reação diferenciada quanto a determinada transgressão, diferenciação essa relacionada aos respectivos modos de dominação exercidos no respectivo campo. Trata do "conjunto de atividades de diferenciação, categorização, hierarquização e gestão social das condutas definidas como indisciplinadas" (Lascoumes, 1996, p. 78-79). Há uma gestão diferencial dos ilegalismos que esclarece o poder disciplinar como mecanismo positivo de produção de sujeitos, e não de mera reação ao desvio, através da hierarquização e diferenciação das infrações. $O$ conceito aparece nas reflexões de Foucault antes mesmo da publicação de Vigiar e Punir, em diversas entrevistas e no curso ministrado entre os anos 1972 e 1973, intitulado A sociedade punitiva: nele defendendo a tese de que determinadas formas de ilegalismo popular, tais como fraudes antifeudais, eram interessantes e funcionais à burguesia durante o Antigo Regime, mas após a tomada de poder no final do século XVIII teriam passado a ser proibidas e duramente controladas (Foucault, 2015, p. 130; Hirata, 2014, p. 99; Telles e Hirata, 2010, p. 39-59).
Para Harcourt, a noção de ilegalismos populares, fundamental para uma concepção de poder disciplinar positivo/produtivo, pode ser interpretada como resposta a leituras de base marxista que conceberam a construção do sistema penal como mera reação a movimentos populares e classes inferiores (Harcourt, 2015, p. 256-258). Foucault afirmou depois, em Vigiar e Punir, que a prisão e as penas

não se destinam a suprimir as infrações; mas antes a distingui-las, a distribuí-las, a utilizá-las; que visam, não tanto tornar dóceis os que estão prontos a transgredir as leis, mas que tendem a organizar a transgressão das leis numa tática geral das sujeições. A penalidade seria então uma maneira de gerir os ilegalismos*, de riscar limites de tolerância, de dar terreno a alguns, de fazer pressão sobre outros, de excluir uma parte, de tornar útil outra, de neutralizar estes, de tirar proveito daqueles. Em resumo, a penalidade não 'reprimiria' pura e simplesmente os ilegalismos*; ela os 'diferenciaria', faria sua 'economia' geral. (...). Os castigos legais devem ser recolocados numa estratégia global dos ilegalismos* (Foucault, 2002, p. 226-227)

Os asteriscos indicam a substituição do termo utilizado na tradução utilizada ("ilegalidades") por "ilegalismos", o qual capta com maior precisão o texto original e todo o potencial crítico do conceito, o qual não se confunde com a acepção tradicional de ilegalidade (sobre, v. Hirata, 2014, p. 98).

Em síntese, portanto, a noção de ilegalismo "é a ideia de que a lei não se destina a ser estritamente aplicada, mas a gerir as margens de legalidade, sendo um instrumento de gestão" (Harcourt, 2015, p. 261). O ponto de contato com o tema em questão é a ideia de "um jogo entre o ilegalismo popular e a lei", ou seja, a hipótese de que o próprio res- 
peito à legalidade "não passava de estratégia no jogo do ilegalismo" (Foucault, 2015, p. 133). De forma mais clara:

não é possível entender o funcionamento de um sistema penal, de um sistema de leis e interditos, se não nos interrogamos sobre o funcionamento positivo dos ilegalismos. É um preconceito de intelectuais acreditar que existem primeiramente interditos e depois transgressões, [ou] acreditar que há o desejo do incesto e depois o interdito do incesto; na verdade, se tivermos de entender e analisar um interdito em relação àquilo que ele proíbe, também será preciso analisá-lo em função daqueles que proíbem e daqueles sobre os quais incide a proibição (Foucault, 2015, p. 134).

Pode-se dizer que uma das mais importantes questões de fundo da sociologia do cárcere sempre foi como é que grande número de pessoas detidas contra sua vontade não permanecem em estado de hostilidade e conflituosidade contínuas (Matthews, 1999, p. 52), construindo-se, ainda que de forma inerentemente instável, ordem e coesão dentro das prisões.

Uma das primeiras e mais conhecidas pesquisas foi publicada em 1940 e, com o conceito de "prisionização", trabalhou com a tese de existência de uma continuidade entre a "subcultura prisional" e aquela dos grupos sociais que compunham a população carcerária desde o exterior (Clemmer, 1940). O trabalho de Clemmer se insere, assim, na perspectiva "da importação", segundo a qual a prisão seria uma espécie de microcosmo da sociedade e uma continuação das práticas criminais das ruas (Morgan e Liebling, 2007, p. 1127). Ela foi contraposta, durante a segunda metade do século $X X$, à perspectiva "indígena" (Morgan e Liebling, 2007, p. 1126), abrangendo as obras de G.
Sykes e E. Goffman, segundo a qual há uma cultura própria das prisões, apartadas que estão da sociedade livre e como "instituições totais".

Após a $2^{a}$ Guerra Mundial, de fato, a sociologia das prisões adquiriu contornos mais claramente estrutural-funcionalistas, partindo desta perspectiva algumas das mais importantes pesquisas na área e suas hipóteses correspondentes. A sociologia com pesquisa empírica nunca foi, por certo, o campo de Foucault, mas seu conceito de ilegalismos é pertinente e coerente à produção na área, sobretudo no sentido de se conceber o sistema disciplinar como sistema de gestão diferenciada de ilegalismos.

É central a ideia, nesse sentido, de que a construção e manutenção da ordem nas prisões não ocorre de forma unilateral ou por um ato de autoridade, e sim a partir da cooperação dos envolvidos. Para Sykes, por exemplo, há padrões de comportamento marcados por "pequenas corrupções" que demarcam as interações entre funcionários e população carcerária, uma relação sempre frágil e instável, na medida em que "a posição dominante do corpo de funcionários é mais ficção que realidade, se pensarmos em dominação como algo mais que formas superficiais e símbolos de poder" (Sykes, 1954, p. 45).

A relevância central de um sistema de premialidade é justamente a de organizar as interações no cárcere a partir de esquemas de recompensas e sanções, mas que não necessariamente permanecerão dentro da legalidade. Segundo Sykes,

a ausência de um senso de dever entre os presos, as falácias óbvias de coerção, a coleção patética de recompensas e sanções 
para induzir cooperação, as fortes pressões em prol da corrupção dos servidores na forma de amizade, reciprocidade, e a transferência de responsabilidades para as mãos de presos de confiança - esses são todos problemas estruturais no sistema de poder nas prisões e não inadequações individuais (Sykes, 1954, p. 61)

A ordem é, portanto, produto de negociação (Morgan e Liebling, 2007, p. 1126) e ainda que o papel exercido pelos agentes penitenciários seja muito relevante nesse sentido, "o equilíbrio prisional resulta de complexa interação entre diversos atores do sistema penal" (Bodê de Moraes, 2013, p. 131). No Brasil, as conclusões são similares, como por exemplo se lê da pesquisa seminal de Coelho em unidade prisional do Rio de Janeiro, no final da década de 80 (Coelho, 1987), e dos trabalhos contemporâneos sobre as relações entre as dinâmicas das redes criminais organizadas fora do cárcere e a ordem prisional (Adorno e Salla, 2007; Dias, 2013).

\subsection{Do sistema disciplinar e a discricionarieda- de administrativa da autoridade penitenciária}

Sob um prisma estritamente jurídico, os temas do sistema disciplinar na execução penal e a discricionariedade administrativa da autoridade penitenciária são bastante problemáticos e sofrem de enorme lacuna teórica, especialmente no campo do que seria um direito administrativo penitenciário, o qual possibilitaria maior controle, pelo direito, dos procedimentos e atos praticados em âmbito prisional.

Entende-se por relação jurídico-administrativa aquela forma de relação jurídica na qual uma das partes é ou atua em nome da Administração Pública. Ressalva-se, desde logo, sua distinção para com a relação jurídica existente entre o condenado o Estado que se refere à pena como consequência do delito, ou seja, a obrigação de sujeição à pena nos termos e limites estabelecidos pela sentença condenatória. O liame jurídico existente entre o condenado e a Administração Pública - a autoridade penitenciária responsável pelo estabelecimento onde cumprirá pena - é o que se denomina relação jurídico-penitenciária, a qual inicia com o ingresso no estabelecimento e se extingue com a sua saída.

Tal relação foi por longo tempo tida como meramente administrativa e mesmo como relação de sujeição. Não obstante, sua natureza é de direito público e deve atender ao reconhecimento do espaço de execução da pena como jurisdicionalizado, o que significou, ao menos em tese, a extensão do princípio da legalidade à execução penal. Trata-se de uma posição bastante recente e vinculada ao advento do Estado Social e Democrático de Direito, da mesma forma como o reconhecimento do recluso como sujeito de direitos se relaciona ao amplo movimento de reconhecimento dos direitos humanos que seguiu à Segunda Guerra Mundial, e do qual é decorrência o documento determinando as "Regras Mínimas para o Tratamento dos Presos", aprovado no $1^{\circ}$ Congresso nas Nações Unidas sobre Prevenção do Crime e Tratamento de Delinquentes (Genebra, 1955), e atualmente denominado Regras de Mandela.

Se o prisma fosse estritamente normativo, não deveriam pairar dúvidas sobre a incidência do princípio da legalidade na execução penal. Porém, uma perspectiva crítica e sociológica reconhece a tensão imanente entre norma jurídica e poder disciplinar no ambiente prisional. Nos casos em tela, espe- 
cificamente relacionados à postura estatal diante das situações de apreensão de telefones celulares ou equipamentos análogos, verifica-se que o único objetivo é "sancionar alguém" pelos itens proibidos apreendidos, sem maiores preocupações com a veracidade ou circunstâncias de obtenção da confissão.

Não se pode ignorar, nesse contexto, a configuração fisiológica de um ambiente de constante tensão entre necessidades disciplinares e o chamado "tratamento penitenciário ressocializante". Não que as finalidades de "ressocialização" sejam sempre estranhas à administração penitenciária; mas elas não constituiriam jamais um escopo prioritário, servindo no máximo como critério acessório a ser valorado no exercício de sua discricionariedade sob o prisma da manutenção da ordem.

A própria definição de disciplina, legalmente vinculada à mera "obediência" (art. 44, LEP), tende a se distanciar do conceito de norma jurídica, na medida em que não há na esfera disciplinar qualquer base contratual a pressupor, mesmo que apenas formalmente, um status de igualdade: na verdade, a hierarquia é o que caracteriza a relação desigual de sujeição que identifica a disciplina. A norma disciplinar tende a ser vaga e genérica, na medida em que sempre abre um espaço não-vinculado, como ocorre, por exemplo, ao se definir o ato de "incitar ou participar de movimento para subverter a ordem ou a disciplina" como falta grave (art. 50, I, LEP).

No início do século XX, particularmente por conta da doutrina alemã (com Otto Mayer, por exemplo), foi criada a doutrina administrativista da "supremacia especial" - também chamada de teoria das relações especiais de poder ou sujeição - a fim de fornecer um suporte teórico aos chamados "espaços livres de direito". Enquanto o poder estatal soberano constituiria um poder de supremacia geral para com os cidadãos, nas relações de sujeição se teria o exercício de um poder de supremacia especial sobre o outro. Logo, ter-se-ia não uma relação do tipo direito/obrigação, como aliás dá a entender a própria Lei de Execução Penal ao falar de direitos e deveres do preso, mas sim de poder/ônus: de um lado o poder de sujeitar; de outro, a obrigação de obedecer.

Por "espaço livre de direito", deve-se entender não exatamente espaço não regulado pelo direito, mas sim espaço não valorado juridicamente, abrangendo comportamentos "juridicamente relevantes e juridicamente regulados, mas que não podem ser adequadamente valorados nem como lícitos nem como ilícitos" (Kaufmann, 2009, p. 338). Entendia-se que as relações de sujeição comportariam a inobservância de direitos fundamentais, considerando a execução da pena como um serviço público prestado pela administração penitenciária e no qual não valeriam sequer os princípios do direito administrativo (Miranda Rodrigues, 2002, p. 81).

Como se vê, a primeira consequência da adoção de uma teoria como esta no âmbito da execução penal é a subtração das interações entre as pessoas presas e as práticas da administração penitenciária a qualquer tutela jurídica, "não valorando" suas dinâmicas, práticas e normas internas. Os direitos fundamentais, mesmo se retoricamente reconhecidos, restam sempre diluídos na relação de sujeição (Fragoso e Catão e Sussekind, 1980, p. 4), fazendo do recluso um cidadão "de segunda categoria" (Rivera Beiras, 1997). 
A teoria parece poder ser visualizada como "sociológica", ou seja, descritiva do "ser", e assim capaz de "dizer a verdade". Caso tal leitura passasse a ser também "prescritiva", como um "dever ser", transformar-se-ia em ideologia tecnocrática inaceitável. Mas como teoria "sociológica", tem respaldo científico: mesmo com o domínio crescente do "jurídico", existem ainda espaços que são, inegavelmente, de relações sociais de sujeição dominadas unilateralmente por poderes que se subtraem, total ou parcialmente, a qualquer predeterminação legal. Trata-se, novamente, da gestão de ilegalismos, e não da legalidade. Tal teorização não diz respeito aos limites que o direito pode ou poderia colocar sobre as relações de domínio. Estas jamais poderão ser completamente preenchidas ou hegemonizadas pelo "direito", na medida em que sempre haverá, mormente no campo carcerário, um núcleo resistente e refratário, mesmo se mínimo, que permanecerá dele "livre".

A teoria da supremacia especial veio a perder espaço doutrinário justamente com a afirmação do Estado de Direito por meio de decisões do Tribunal Constitucional alemão (Miranda Rodrigues, 2002, p. 81), adotando como parâmetros a limitação do poder perante os cidadãos e a transformação das "relações de poder" em relações jurídicas de direitos e deveres.

De outro lado, a doutrina norte-americana das "hands-off" declinava a intervenção do Poder Judiciário na tutela de relações que concerniam exclusivamente à Administração Pública, legitimando, assim, uma política de afastamento e não-interferência na execução penal. Pode-se mencionar ao menos dois fundamentos comumente arguidos pela doutrina do hands-off (Vogelman, 1971, p. 53): o princípio da separação de poderes e o temor de que a intervenção judicial prejudicasse os objetivos imediatos da administração do estabelecimento penitenciário, que são a manutenção da ordem e da segurança internas. Por exemplo, na decisão da Corte da Virgínia no caso Ruffin vs. Commonwealth (1871), indicando o condenado como "escravo do Estado" (Hawkins, 1976, p. 136).

A ampliação da possibilidade de questionamento judicial da situação das prisões se deu a partir de algumas decisões históricas, desde Coffin vs. Reichard (1944), trazendo o princípio segundo o qual o "prisioneiro mantém todos os direitos de um cidadão normal a não ser aqueles expressamente, ou por implicação necessária, afastados juridicamente", até sucessivos julgamentos que, a partir da década de 60 (Fragoso e Catão e Sussekind, 1980, p.19), e especialmente com Monroe vs. Pape (1961), passaram a admitir a apreciação judicial da ilegalidade das condições carcerárias.

Estabeleceu-se, então, a necessidade de se realizar, no caso concreto, um juízo de ponderação entre os interesses do recluso e do estabelecimento, porém com um importante ganho: em nenhuma hipótese, mesmo com motins ou perturbações excepcionais da ordem interna, a administração penitenciária teria legitimidade para negligenciar direitos fundamentais dos reclusos não atingidos pela sentença condenatória, como, por exemplo, o direito à alimentação.

O princípio da individualização da sanção disciplinar é previsto pelo art. 45, §3 , da LEP, proibindo a responsabilização coletiva e objetiva. O princípio exige a comprovação da autoria do imputado pela respectiva falta disciplinar, cumprindo a mesma função do princípio da culpabilidade, pois "não será 
factível imputar uma infração sem a prévia constatação do vínculo subjetivo com o autor" (Cesano, 2007, p. 211).

Ora, tanto a permissão tácita do Estado para que a população carcerária negocie e faça da assunção de responsabilidade por itens proibidos apreendidos uma mercadoria e elemento fundamental em suas dinâmicas, como a indiferença em relação ao conceito de prova e à lógica do in dubio pro reo no momento de julgamento da infração disciplinar, reconfirmam a presença de espaços livres do direito abertos por quem, discricionariamente, pode também negá-los.

Em outros termos, a demanda da autoridade penitenciária por um "culpado", ainda que não seja ele, sabidamente, o "efetivo dono" do celular, fazendo o próprio Estado aderir às dinâmicas criadas pela população carcerária, não é uma postura que pode ser compreendida dentro do quadro do juridicamente permitido/proibido, mas constitui, por outro lado, componente decisivo na construção e na manutenção da ordem interna da unidade prisional.

\section{As faltas graves referentes a forneci- mento, posse ou uso de telefone celular (ou componente acessório) no ano de 2017 na Casa de Custódia de Curitiba (CCC)}

A Casa de Custódia de Curitiba foi inaugurada em agosto de 2002 e tem capacidade para 420 pessoas, contando, no último dia de 2017, com 621 presos, todos homens. ${ }^{4}$ Com o Decreto n'. 5502/2012-PR, do Governo do Paraná, passou a ser destinada "exclu- sivamente ao encarceramento de homens autores de crimes contra a mulher" (art. $1^{\circ}$ ), sendo por isso conhecida na região como uma "prisão-seguro":

\begin{abstract}
Art. $1^{\circ}$ A Casa de Custódia de Curitiba - CCC será destinada exclusivamente ao encarceramento de homens autores de crimes contra a mulher, observando-se, preferencialmente, a seguinte ordem: I - crimes contra a dignidade sexual; II - crimes praticados contra a pessoa; III - crimes praticados com grave ameaça ou violência. Parágrafo único. As eventuais vagas remanescentes serão destinadas ao encarceramento de homens autores de outros crimes praticados contra a mulher (Decreto 5502/2012, publicado no DO 8871-PR)
\end{abstract}

Na prática, há três galerias que concentram condenados por crimes contra a dignidade sexual - mas não apenas tendo vítimas muIheres - e outros classificados como "oposição", termo nativo que designa aqueles que são contrários à hegemonia da facção paulista, fortemente presente no Estado do Paraná, conhecida como Primeiro Comando da Capital ("PCC").

Pode-se trabalhar com a tese, com base em outros trabalhos sobre o tema (Dias, 2013, p. 226), de que a população carcerária desse tipo de unidade é mais vulnerável à violência e à sujeição nas interações entre os próprios presos e sobretudo a abusos da autoridade administrativa, na medida em que a citada organização teria produzido uma espécie de "monopólio da violência" nas unidades por ela "controladas". A CCC estaria dentro do que Dias chama de "zonas de exclusão":

A ordem social construída através da imposição da paz pelo PCC tem como seu reverso zonas de exclusão, nas quais se encontram os párias que não cabem na unidade que foi constituída a partir da 
consolidação de seu poder, (...) [tendo ao menos três efeitos]: permanência em celas superlotadas, restrições à progressão de regime - uma vez que a absoluta maioria das unidades prisionais de regime semiaberto está sob o controle do PCC - e, sobretudo, exposição a uma violência institucional mais acirrada (Dias, 2013, p. 437-438).

Trata-se de uma cadeia pública, pois destinada, a princípio, a presos provisórios, mas abriga muitos condenados, cumprindo função de penitenciária. O espaço físico é dividido entre o setor administrativo, o qual congrega as salas da direção, vice direção, psicologia, assistência social, entre outros, e o setor cuja entrada é proibida sem autorização, pois dá acesso à chefia de segurança e às três galerias. Há restrição ao uso de celular apenas neste último, onde são realizados os procedimentos de oitiva e colheita de depoimentos dos presos que respondem a alguma infração disciplinar. As reuniões do Conselho Disciplinar ocorrem no setor administrativo, sem a participação dos presos, mas somente da defesa técnica.

O rito a ser seguido em casos de infração disciplinar é definido, do ponto de vista normativo, pelo Estatuto Penitenciário do Estado do Paraná. ${ }^{5}$ O primeiro - e decisivo - ato é a elaboração de comunicado disciplinar diante da ocorrência de determinada infração, o que é feito pelo agente ou servidor que tem o primeiro contato com a situação. O comunicado é encaminhado à direção da unidade, a qual o remete ao Conselho Disciplinar. Após a oitiva do preso e eventuais testemunhas, a situação é levada a julgamento em sessão do Conselho, colegiado composto por quatro técnicos e o diretor, além do secretário, da defesa técnica e da chefia do setor de segurança, a qual é necessariamente ouvida antes da realização de defesa oral.

Durante o ano de 2017, foram lavrados 16 comunicados disciplinares envolvendo apreensão de aparelhos de telefone celular ou um de seus componentes acessórios. A posição jurisprudencial majoritária admite como falta grave também a posse de acessórios de telefone celular, como chips e carregadores de bateria. Ela se sustenta em precedentes do STF (como no HC 105973) RS) e STJ. Há evidente violação, porém, do princípio da legalidade estrita, tratando-se de analogia in malam partem (Roig, 2018, p. 237).

Para cada comunicado disciplinar, um preso foi sancionado administrativamente por falta grave. Em mais da metade dos casos, como sintetizado no quadro abaixo, a falta grave foi afastada em análise judicial. Isso evita a repercussão por sobre o processo executório, mas a análise judicial ocorre em um momento posterior ao esgotamento dos efeitos administrativos das sanções de isolamento e suspensão de direitos, as quais incluem a suspensão do direito de visitas de familiares, variável que ganha grande relevância nas falas dos detentos. A tabela abaixo sintetiza os dados e a referência exata de onde foram extraídos os depoimentos dos presos: 


\begin{tabular}{|c|c|c|c|c|}
\hline \multicolumn{5}{|c|}{$\begin{array}{l}\text { RELAÇÃo de FALTAS GRAVES ENVOLVENDO CELULAR OU SIMILAR (ART. 50, VII, LEP) } \\
\text { NA CASA DE CUSTÓdIA DE CURITIBA (CCC) NO ANO DE } 2017\end{array}$} \\
\hline & Autos (processo eletrônico - PROJUDI/PR*) & $\begin{array}{l}\text { Data } \\
\text { da } \\
\text { falta }\end{array}$ & $\begin{array}{l}\text { Movimento do } \\
\text { PAD** }\end{array}$ & Em juízo*** \\
\hline 1 & 0007550-47.2013.8.16.0009 & $9 / 2$ & 60.1 & Falta afastada (Mov. 72.1). \\
\hline 2 & $0006842-71.2010 .8 .16 .0083$ & $9 / 2$ & 97.1 & Falta afastada (Mov. 109.1). \\
\hline 3 & $0003798-04.2012 .8 .16 .0009$ & $9 / 2$ & 45.1 & Homologada (Mov. 49.1). \\
\hline 4 & $0002186-60.2014 .8 .16 .0009$ & $9 / 2$ & 93.1 & Não apreciada. \\
\hline 5 & 0001335-84.2015.8.16.0009 & $28 / 4$ & 80.1 & Homologada (Mov. 119.1). \\
\hline 6 & 0000437-42.2013.8.16.0009 & $22 / 6$ & 172.1 & Homologada (Mov. 225.1). \\
\hline 7 & $0000468-23.2017 .8 .16 .0009$ & $6 / 7$ & 219.1 & Homologada (Mov. 230.1). \\
\hline 8 & 0001988-59.2014.8.16.0094 & $31 / 7$ & 92.1 e 94.1. & Homologada (Mov. 106.1) \\
\hline 9 & 0015336-59.2016.8.16.0035 & $5 / 8$ & Não juntado. & Falta afastada (Mov. 64.1). \\
\hline 10 & 0002191-82.2014.8.16.0009 & $2 / 8$ & 227.1. & Falta afastada (Mov. 236.1). \\
\hline 11 & 0002753-28.2013.8.16.0009 & $2 / 8$ & 84. & Falta afastada (Mov. 111.1). \\
\hline 12 & 0015539-58.2014.8.16.0013 & $2 / 8$ & Não juntado. & $\begin{array}{l}\text { Prisão preventiva (sem processo } \\
\text { de execução). }\end{array}$ \\
\hline 13 & $0011864-37.2015 .8 .16 .0083$ & $2 / 8$ & 169. & Falta afastada (Mov. 177.1). \\
\hline 14 & 0004631-56.2011.8.16.0009 & 29/11 & Não juntado. & Falta afastada (Mov. 128.1) \\
\hline 15 & 0026016-82.2015.8.16.0021 & 29/11 & 122.1. & Falta afastada (Mov. 143.1) \\
\hline 16 & 0000533-86.2015.8.16.0009 & $29 / 11$ & 103.1. & Falta afastada (Mov. 137.1). \\
\hline
\end{tabular}

*Acesso público via http://www.projudi.tjpr.jus.br.

** PAD: Processo Administrativo Disciplinar.

*** Mov.: "Movimento" se refere à referência para localização do ato processual no processo eletrônico.

Há elementos notáveis para compreensão da organização e gestão dos ilegalismos na referida unidade prisional. Primeiramente, a quantidade de dezesseis aparelhos ou componentes apreendidos pode ser considerada baixa, considerado o lapso temporal de 1 ano e que as apreensões se concentram em apenas 8 datas diferentes, sempre em procedimentos de revista nas celas. $O$ ingresso de celulares é atribuído, como regra, ao arremesso desde o lado de fora da unidade, que é localizada em meio a região fortemente arborizada. Não há registro formal de averiguação de práticas de corrupção por servidores, embora esta seja também uma possibilidade, considerada sua frequência no Paraná e em todo o país.
Em segundo lugar, a sugestão de existência de uma grande cifra oculta decorre da constatação de que não há uma efetiva política de fiscalização permanente quanto à presença de celulares circulando nas galerias, concentrando-se a maior parte das apreensões nos procedimentos de "revista geral", e não em práticas de fiscalização inseridas na rotina diária. A gestão da proibição legal como estratégia, portanto, ou a norma legal como recurso a ser ativado ou não-ativado, conforme a conveniência do caso concreto, podem estar tanto no consentimento tácito em relação à presença e circulação de itens proibidos como na própria discricionariedade concreta presente no ato de elaboração ou não de comunicado disciplinar, res- 
saltando-se que tal discricionariedade não está abarcada pelas normas legais na medida em que a lavratura do ato, em tese, é ato de ofício e sua não realização poderia configurar crime contra a administração pública. Mas se estamos diante de ilegalismos dos quais apenas alguns serão alçados à condição formal de "falta disciplinar", a abstenção de atos de ofício diante de infrações é uma prática muito mais complexa e que se insere na teia de interações fundadas na cooperação visualizadas, descritivamente, como elementos essenciais para construção da ordem interna.

É na análise das "falas" de presos e servidores extraídas prevalentemente dos autos de procedimento administrativo disciplinar, mas também das interações e manifestações nas sessões de julgamento, que se pode compreender a questão de pesquisa colocada no início, ou seja, quais seriam os critérios e parâmetros para imputação da responsabilidade pela prática da infração disciplinar, quando registrada.

Já no caso $n^{\circ} 1$, seguindo sempre a numeração da coluna à esquerda na tabela acima transcrita, tem-se um caso de "confissão impossível": o preso afirmou na unidade prisional que os 7 (sete) celulares apreendidos seriam de sua propriedade. Em juízo, negou que seriam efetivamente seus e a falta foi afastada.

Situação similar à do caso $\mathrm{n}^{\circ} .13$, em que o preso assumiu ser dono de 3 (três) celulares no procedimento administrativo, e em juízo dito que o fez porque foi ameaçado. No caso $\mathrm{n}^{\circ} .2$ há assunção da responsabilidade pelos objetos, tanto em juízo como na fase administrativa, tendo a falta também sido afastada por ausência de credibilidade e factibilidade da própria confissão realizada.
Em todos eles porém, foram aplicadas as sanções administrativas em seu grau máximo, as quais tiveram esgotados seus efeitos antes mesmo da análise judicial.

No caso $n^{\circ}$. 6, em seu depoimento prestado na unidade prisional, o preso afirmou:

\begin{abstract}
muitas coisas acontecem dentro desse lugar e ninguém sabe como acontece, e a palavra do funcionário tem a fé pública, somos tachados como mentirosos e pra evitar problema a pais de famílias que estão para ir embora em um ano ou dois, assim como tenho alguns anos a cumprir e para evitar problemas aos meus companheiros assumi a posse dos objetos.
\end{abstract}

Há referência, portanto, à assunção da propriedade pelos objetos apreendidos para evitar que "pais de família" - que têm a expectativa da visita de seus filhos, portanto - e "que estão para ir embora" - cientes de que a confirmação judicial de falta grave interrompe a contagem do requisito temporal para progressão de regime (Súmula $n^{\circ}$. 534, do STJ) - sejam prejudicados.

No caso $n^{\circ}$. 8, o preso afirmou no processo administrativo disciplinar que "não tem dinheiro para comprar celular, mas estava guardando os telefones e por isso assumiu a posse", evidenciando que a ação é valorada como mercadoria ou "serviço" que pode ser prestado a título de pagamento de dívidas, contraprestação por favores anteriores ou por remuneração direta. Em juízo, no mesmo processo, ele ainda agrega outro dado:

Eu teria que assumir, pois eu era a pessoa que possuía mais condenações dentro da cela. Eles me dariam $\mathrm{R} \$ 1500$ ( $\mathrm{R} \$ 500$ por aparelho) para assumir os objetos. Usei uma vez dos aparelhos. Cada telefone custa $\mathrm{R} \$ 10.000$ dentro da unidade. 
A utilização da expressão "eu teria que assumir" indica não exatamente uma escolha, mas a adesão a regras de organização interna. O fato de ter uma pena remanescente longa a ser cumprida é mencionado, aqui, como justificativa racional para a assunção da responsabilidade, evitando prejuízos a outros que estejam próximos de alcançar o requisito objetivo para a progressão de regime ou para o livramento condicional.

No caso $n^{\circ}$. 7, a pessoa presa admitiu "estar guardando" o celular para terceiro, no mesmo sentido acima indicado. No caso $n^{\circ} 9$, afirmou que "não era seu, estava apenas levando para dentro". No $n^{\circ}$. 12, o acusado afirma claramente que "às vezes guarda objetos para presos de vários outros barracos".

Outras afirmações marcantes como "eu assumo a responsabilidade para não complicar os demais" (n. 14); "eu estava em posse destes objetos até mesmo porque seria desta maneira que conseguiria falar com a Direção, porque quero ser transferido para Santa Catarina, onde reside minha família. Aqui não tenho nada, nem família, sacola, nada. Esta foi a maneira que infelizmente eu achei para chamar atenção" ( $n^{\circ}$. 15) indicam algumas permanências nas justificações conferidas às supostas confissões, todas sempre chanceladas pelo respectivo Conselho Disciplinar sem maiores questionamentos ${ }^{6}$ : a) presos que assumem a responsabilidade porque não tem família na região e, portanto, não têm visita; b) porque têm longa pena remanescente e estão mais distantes do que os demais do alcance do

\footnotetext{
6 Mencionaria ainda situação fora do espectro da pesquisa, pois ocorrida em sessão de julgamento do Conselho Disciplinar da CCC em 27 de março de 2018 , em que o preso que assumiu a responsabilidade pelos itens proibidos apreendidos sequer fazia parte do cubículo/cela no qual os itens foram encontrados. O colegiado do Conselho se recusou a aceitar a confissão neste caso ("gente, aí já é demais", afirmou uma das técnicas) mas ao invés de afastar a falta por ausência de qualquer prova de autoria, o PAD foi enviado a diligências porque segundo fala da chefia de segurança, "alguém terá que assumir até a próxima reunião".
}

direito à progressão de regime ou ao livramento condicional; c) porque são remunerados ou devem quitar dívidas através do serviço de "guardar" os aparelhos e assumir a responsabilidade em caso de apreensão.

Tais padrões foram, por mais de uma vez, explicados pela chefia de segurança da unidade prisional aos membros do Conselho Disciplinar durante as reuniões, sem que isso interferisse na posição unânime em prol da aplicação de falta grave. Como bem indicou Cicourel, é fundamental identificar os "constructos de senso comum" que delimitam a compreensão das coisas pelos atores sociais:

\begin{abstract}
Se é correto supor que as pessoas, na sua vida cotidiana, ordenem seu meio, atribuam significados e relevâncias a objetos, fundamentam suas ações sociais em racionalidades de senso comum, não se pode fazer pesquisa de campo ou usar qualquer outro método de pesquisa nas ciências sociais sem levar em consideração o princípio da interpretação subjetiva. Enquanto conversa com as pessoas investigadas no campo, fazendo perguntas estruturadas ou não estruturadas em situação de entrevista ou usando o questionário, o observador científico deve levar em conta os constructos de senso comum empregados pelo ator na vida cotidiana se quiser compreender os significados atribuídos às suas perguntas pelo ator, qualquer que seja a forma pela qual elas foram apresentadas ao ator. (Cicourel, 1980, p. 110).
\end{abstract}

Observando ser imprescindível a articulação de crítica estrutural em conjunto ao referido princípio da interpretação subjetiva, o que se buscou minimamente fazer a partir das discussões teóricas articuladas acima, o que se pode constatar é que, fundadas em normas impositivas criadas pela população carcerária, em atitudes de solidariedade ou em movimentos de natureza comercial, 
as práticas de falsa assunção de responsabilidade são naturalizadas e não são vistas como um "problema jurídico" pelos membros do Conselho Disciplinar.

A própria defesa técnica - destacando-se aqui que o lugar do pesquisador era justamente sobreposto ao papel exercido como defensor público - muitas vezes também adere a tal naturalização, buscando prioritariamente evitar os riscos de aplicação de outras sanções, de natureza média, aos demais presos do cubículo "que não assumiram" nenhum objeto. O Estatuto Penitenciário do Estado do Paraná prevê falta média consistente em "dificultar averiguação, ocultando fato ou coisa relacionada com a falta de outrem" (art. 62, III). Embora aplicá -la a todos os presos de cela seja evidente e inadmissível sanção coletiva, o controle judicial a posteriori frequentemente esbarra na perda de objeto, posto que já exauridas as sanções exclusivamente administrativas consistentes em isolamento e suspensão de direitos por até 20 dias.

Não se trabalha, a rigor, com o conceito jurídico de prova, mas sim com concepção estratégica de poder disciplinar segundo a qual o que importa é haver um "culpado", seja quem for ou em quais circunstâncias, pois é este o elemento que se faz importante nas dinâmicas de afirmação - meramente simbólica - da autoridade penitenciária e manutenção da ordem interna. Não havendo mecanismos eficientes de investigação e instrução, prevalece a lógica de que simplesmente afastar a falta por insuficiência de provas de autoria equivaleria a "liberar" a utilização de celulares no interior das galerias. Trata-se de uma postura caracterizável como gestão estratégica de ilegalismos, e não de combate efetivo a determinada prática infracional.
Em síntese, dos 16 casos do ano de 2017 encaminhados pelo presídio ao juízo de execução penal, em somente 5 deles a falta foi confirmada (casos $n^{0} .3,5,6,7$ e 8) e em 9 ocasiões a falta foi afastada em juízo (casos $n^{\circ} 1,2,9,10,11,13,14,15$ e 16). Os outros 2 processos se referem a um em que o incidente não foi apreciado, sem maiores explicações $\left(n^{\circ} 4\right)$ e um último sem processo executório, tendo a sanção sido aplicada exclusivamente em âmbito administrativo ( $\left.n^{\circ} .12\right)$.

Vale notar que em 6 situações (casos $n^{\circ} 1,2$, $9,13,14$ e 16) vários objetos foram assumidos pela mesma pessoa, tendo a falta sido afastada judicialmente exatamente por ausência de credibilidade da confissão e de outras provas de autoria.

Em apenas 2 situações (casos $n^{\circ} .3$ e 5 ) as circunstâncias são "regulares": apenas um aparelho apreendido, confissão na fase administrativa e em juízo, com homologação judicial da falta. E em ambas, os imputados afirmaram fazer uso dos celulares somente para contato com a família.

Além das relações comerciais e dinâmicas de opressão que podem se fazer presentes nas interações da população carcerária, a indiferença do Conselho Disciplinar à lógica do in dubio pro reo e a exigência de "um culpado", com medidas de retaliação caso ninguém assuma a responsabilidade pelos objetos, contribui para a concretização desse grande "teatro da disciplina".

Como se vê, não há parâmetros estáveis, coerentes e consolidados na análise do Poder Judiciário das situações descritas, mas é possível constatar, ao menos na pequena amostra indicada, uma tendência a repelir imputações de responsabilidade artificiais e escancaradamente distantes da realidade. 
De todo modo, a proporção considerável de faltas afastadas judicialmente - quase 70\% não interfere na postura do Conselho Disciplinar em âmbito administrativo. Pelo contrário: há plena consciência de que boa parte das faltas graves aplicadas administrativamente será judicialmente anulada, e este é tomado como elemento natural de racionalização da importância de se "sancionar alguém". Afinal, as sanções administrativas de isolamento e, principalmente, suspensão de direitos, sendo central a suspensão do direito de receber visita dos familiares, já terão sido integralmente aplicadas quando o caso chegar às mãos do juízo de execução. Logo, os efeitos disciplinares da medida terão se exaurido sem qualquer controle posterior, o que indica, uma vez mais, a caracterização de tais práticas como gestão diferenciada de ilegalismos. Não é de direito que falamos aqui, mas de suas entrelinhas, seus espaços vazios e "livres", espaços dos quais o cárcere, expressão máxima do "não-jurídico", constitui a prática e a instituição por excelência.

\section{Considerações finais}

O recorte empírico da pesquisa aqui apresentada expressa parte de questão maior, pertinente à necessária contraposição entre as finalidades declaradas do sistema disciplinar (e da proibição absoluta do uso de telefones celulares nos presídios) e as funções reais materializadas pelas suas práticas cotidianas.

Do ponto de vista metodológico, um primeiro desafio foi a ocultação da condição de pesquisador e a entrada no campo como profissional do sistema de justiça, ou seja, como nativo, condição quase inescapável no campo do direito (Baptista, 2017, p. 92), parte integrante do próprio objeto. O pa- pel do defensor público é, em parte, legitimante, posto que sua presença é necessária para evitar a nulidade do procedimento, e sua atuação, ainda que possa e deva ser combativa e pautada pelo viés de redução de danos, está tão sujeita à naturalização do campo como qualquer outro papel institucional dentro do sistema de justiça. Necessária, portanto, a demarcação de um mínimo distanciamento para a construção da reflexão, o que não se confunde, por óbvio, com qualquer pretensão de neutralidade científica.

Optei, por cautela e considerando potenciais problemas éticos, por priorizar como fonte a análise de informações públicas, ou seja, os depoimentos dos presos que confessaram autoria quanto à posse dos itens proibidos apreendidos, extraídos dos processos administrativos disciplinares de seus respectivos processos executórios. Toda a interpretação de seu contexto e sentido, porém, decorrem da inserção como observador durante o ano de 2017. No fim das contas, o fato de que os presos que são sancionados pela falta grave não são efetivamente os responsáveis é algo bastante explícito e tranquilamente absorvido no campo da unidade prisional, embora tal "sinceridade" permaneça adstrita ao ambiente carcerário - basta ver a proporção considerável de faltas graves afastadas em juízo por insuficiência de provas.

À luz de qualquer parâmetro de utilidade ou eficácia, a proibição de telefones celulares nos presídios brasileiros é medida patética e plena de hipocrisia quanto a suas finalidades declaradas, contribuindo apenas para o agravamento qualitativo das condições de vida no cárcere, já pautadas pela precariedade e violência. É que o objetivo de coibir ações criminosas ordenadas de dentro do sistema prisional está muito distante de ser 
alcançado. Ainda que não tenha sido objeto direto desta pesquisa, pode-se afirmar com tranquilidade que a regra é a apreensão de celulares utilizados para o contato com a família e amigos (vide observação acima sobre os casos $n^{\circ} .3$ e 5), não para cometer crimes. E o que dizer de eventual inserção e manutenção de celulares pelo próprio Estado para fins de monitoramento de movimentos ilícitos, como parte das chamadas "ações de inteligência"?

Os resultados da amostra empírica delimitada a uma unidade prisional de Curitiba/ PR indicam a imputação de responsabilidade disciplinar pelas faltas graves a presos sabidamente inocentes, mas que "assumem" a responsabilidade por não terem família na região (não perdendo visitas com a suspensão decorrente da sanção administrativa) , por terem uma pena remanescente alta (estando mais distantes do que os demais do alcance do direito à progressão de regime ou ao livramento condicional) ou ainda tendo por objetivo uma contraprestação pecuniária ou outros favores. Coberto de razão está Roig quando afirma que "o proibicionismo generalizado que envolve esta falta disciplinar (...) acaba fomentando a corrupção, troca de favores, privilégios espúrios e produção de danos (custos sociais) desnecessários à maioria das pessoas presas que não possuem propósitos ilícitos" (Roig, 2018, 242).

Ocorre que o Estado presentado pela autoridade penitenciária, sabendo disso e ainda assim aplicando as sanções disciplinares, tendo conhecimento inclusive da possibilidade de afastamento da falta em juízo, está chancelando dinâmicas e relações ilícitas entre os presos, muitas vezes fundadas na exploração e opressão, estimulando, e não combatendo, esse tipo de prática e orga- nização. A abordagem por meio da noção foucaultiana de ilegalismo vem enfatizar o escopo de gestão diferencial, e não de supressão, dos ilegalismos, os quais "não são nem disfunções das tecnologias políticas e nem exceções de suas práticas legais, mas sim parte absolutamente constitutiva do exercício do governo" (Hirata, 2014, p. 101).

Ainda assim, diversas medidas poderiam ser adotadas como forma de redução de danos e minimização das violações de direitos, tais como a abertura de maior controle judicial sobre o sistema disciplinar através da regulamentação do conceito de prova nos processos administrativos disciplinares, a alteração do art. 50, VII da LEP inserindo a necessidade de elemento subjetivo especial vinculando o objetivo do uso do celular à prática de novos crimes ou mesmo a instalação de telefones públicos monitorados nas penitenciárias e cadeias públicas, como já vem sendo proposto em alguns projetos de lei em tramitação no Congresso Nacional. Nenhuma delas, porém, alteraria a configuração das interações do ambiente prisional e os mecanismos de construção de sua ordem interna como pautadas não pelo binômio lícito/ilícito, mas sim pela diretriz de gestão diferenciada de ilegalismos.

\section{Referências}

Adorno. S. (1991). A prisão sob a ótica de seus protagonistas: itinerário de uma pesquisa. Revista Tempo Social, 3(1-2), 7-40

Angrosino, M. (2009). Etnografia e observação participante.Porto Alegre: Artmed

Apa, Z.; YuBai, R.; Mukherejee, D.; Herzig, C.; Koenigsmann, C.; Lowy, F.; Larson, E. (2012). Challenges and strategies for research in prisons. Public Health Nurs, 29 (5), 467-472.

Baptista, B. L. (2017). O uso da observação participante 
em pesquisas realizadas na área do Direito: desafios, limites e possibilidades. In M. Machado (Org.),Pesquisar empiricamente o Direito (pp. 83-118). São Paulo: Rede de Estudos Empíricos em Direito.

Becker, H. (1999). Métodos de pesquisa em Ciências Sociais. 4. ed. São Paulo: Hucitec.

Bodê de Moraes, P. (2013).A identidade e o papel de agentes penitenciários. Revista Tempo Social, 25(1), 131-147.

Braga, A. G. M. (2014). Criminologia e prisão: caminhos e desafios da pesquisa empírica no campo prisional. Revista de Estudos Empíricos em Direito, 1(1), 46-62.

Brasil. Lei 7.210, de 11 de julho de 1984 (Lei de Execução Penal). Diário Oficial da República Federativa do Brasil, Poder Executivo, Brasília, DF.

Brasil. Lei 11.466, de 28 de março de 2007. Diário Oficial da República Federativa do Brasil, Poder Executivo, Brasília, DF.

Cesano, J. D. (2007). Derecho penitenciario: aproximación a sus fundamentos. Córdoba: AlveroniEdiciones. Chauvin, S.; Jounin, N. (2015). A observação direta. In S. Paugan(coord.). A pesquisa sociológica (pp. 124-140). Petrópolis: Vozes.

Cicourel, A. (1980). Teoria e método em Pesquisa de campo. In A. Zaluar (org.). Desvendando máscaras sociais (pp. 87-121). Rio de Janeiro: Francisco Alves Editora.

Clemmer, D. (1940). The prisoncommunity. Boston: Christopher Publishing House.

Coelho, E. C. (1987). A Oficina do Diabo: Crise e conflitos no Sistema Penitenciário do Rio de Janeiro. Rio de Janeiro: Iuperj.

Dias, C. C. N. (2013). PCC: hegemonia nas prisões e monopólio da violência. São Paulo: Saraiva.

Foucault, M. (2015). A sociedade punitiva: curso no Collège de France (1972-1973). São Paulo: Martins Fontes.

Foucault, M. (2002). Vigiar e punir. $25^{\mathrm{a}}$ ed. Rio de Janeiro: Vozes.

Fragoso, H.; Catão, Y.; Sussekind, E. (1980). Direitos dos Presos. Rio de Janeiro: Forense.

Haguette, T. (2000). Metodologias qualitativas na sociologia. Petrópolis: Vozes.

Harcourt, B. (2015). Situação do curso. In M. Foucault. A sociedade punitiva: curso no Collège de France (19721973) (pp. 241-281). São Paulo: Martins Fontes.

Hawkins, G. (1976). The prison: policy and practice. Chicago: The University of Chicago Press.

Hirata, D. (2014). Ilegalismos. In R. S. Lima; J. L. Ratton;
R. G. Azevedo (org.). Crime, Polícia e Justiça no Brasil (pp. 97-104). São Paulo: Contexto.

Jaccoud, M.; Mayer, R. (2008). A observação direta e a pesquisa qualitativa. In J. Poupart; J.P. Deslauriers; L.H. Groulx; A. Laperrière; R. Mayer; A. Pires (org.). A pesquisa qualitativa: enfoques epistemológicos e metodológicos (pp. 254-294). $4^{\mathrm{a}}$ ed. Petrópolis: Vozes.

Lascoumes, P. (1996). L'illégalisme, outil d'analyse. Sociétés et représentations, 3, 78-84.

Kaufmann, A. (2009). Filosofia do direito. 3. ed. Lisboa: Fundação CalousteGulbenkian.

Machado, M. R. (org.) (2017). Pesquisar empiricamente o Direito. São Paulo: Rede de Estudos Empíricos em Direito.

Martin, C. (2000).Doing research in a prison setting. In V. Jupp; P. Davies; P. Francis (ed.). Experiencing Criminological Research (pp. 215-233). London: Sage,

Matthews, R. (1999). Doing time: an introduction to the sociology of imprisonment. New York: MacMillan Press.

Miranda Rodrigues, A. (2002). Novo olhar sobre a questão penitenciária. 2. ed. Coimbra: Coimbra Editora.

Morgan, R.; Liebling, A.(2007). Imprisonment: an expanding scene. In M. Maguire; R. Morgan; R. Reiner (ed.). The Oxford Handbook of Criminology (pp. 11001138). $4^{\text {a }}$ ed. Oxford: Oxford University Press.

Rivera Beiras, I. (1997). La devaluación de los derechos fundamentales de los reclusos: la construcción jurídica de un ciudadano de segunda categoría. Barcelona: J. M. Bosch Editor.

Roig, R. D. E. (2018). Execução Penal: teoria crítica. $4^{a}$ ed. São Paulo: Saraiva.

Sá, P. P.; Simões, H. V.; Bartolomeu, P. C. (2017). Vale quanto pesa: o que leva $(\mathrm{m})$ mulheres grávidas à prisão?. Revista de Estudos Empíricos em Direito,4(3), 145-161.

Sykes, G. (1954). The society of captives: a study of a maximum security prison. New Jersey: Princeton University Press.

Vogelman, R. (1971). Prison restrictions - Prisoner Rights. In L. Radzinowicz; M. Wolfgang (org.). Crime and Justice III: The Criminal in Confinement (pp. 52-68). London: Basic Books.

Data de submissão: 21/09/2018

Data de aceite: 19/07/2019 